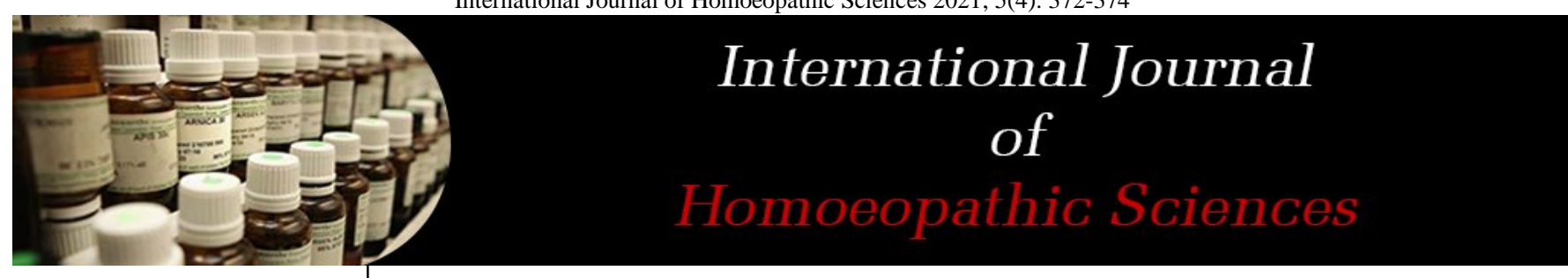

E-ISSN: 2616-4493

P-ISSN: 2616-4485

www.homoeopathicjournal.com

IJHS 2021; 5(4): 372-374

Received: 14-07-2021

Accepted: 07-09-2021

Bala Krishna Rao Dabbir Sreepathi Veterinary Services, Kadapa, Andhra Pradesh, India

Sreekumar Sankaran Holistic Veterinarians, ISKCON Belgaum, Tilakwadi, Belgaum, Karnataka, India

Sreekala Vijayalaksmi Holistic Veterinarians, ISKCON Belgaum, Tilakwadi, Belgaum, Karnataka, India

\section{Treatment of retention of fetal membranes in ruminants with pyrogenium 200}

\author{
Bala Krishna Rao Dabbir, Sreekumar Sankaran and Sreekala \\ Vijayalaksmi
}

DOI: https://doi.org/10.33545/26164485.2021.v5.i4f.497

\begin{abstract}
One of the most common postpartum disorders encountered in cows is retention of foetal membranes. The foetal membranes should be retained, if it is not expelled during the first 8 hrs after parturition. Retained foetal membranes in livestock have adverse effects on fertility and production. Diverse therapeutics has been employed for treatment of retention of foetal membranes. Manual removal, administration of intra-uterine and/or systemic antibiotics, injection of oxytocin, PGF2 $\alpha$ and $\beta 2$ receptor blockers. Manual removal of the retained membranes is no longer recommended and is potentially harmful. The methods tried were costly, required long duration and services of veterinarians and para veterinarians are and demonstrated that the methods were ineffective. An attempt is made to try homeopathic remedy Pyrogenium 200C in 143 animals and found very effective, economical remedy and the administration of the remedy does not call for the assistance of technical persons.
\end{abstract}

Keywords: Retention of foetal membranes-efficacy of pyrogenium 200C- livestock

\section{Introduction}

One of the most common postpartum disorders encountered in cows is retention of foetal membranes ${ }^{[1]}$. Roberts ${ }^{[2]}$ stated that the foetal membranes should be retained, if it is not expelled during the first 8 hrs after parturition. (Fig 1)

Markusfeld ${ }^{[3]}$ reported that practically all cases of retention of foetal membranes which are more than 24 hrs terminate in secondary metritis. An increased recurrence risk ratio for retention of fetal membranes is seen in second, third and fourth calving's for Swedish Red and White Breed and in second and third calving's for Swedish Friesian Breed ${ }^{[4]}$. Retention of foetal membranes were associated with 2 to 3 more days to 1 st service and 4 to $10 \%$ lower conception rates at 1st service, resulting in an average of 6 to 12 additional days to conception in cows with RFM versus cows without retention of feta membranes ${ }^{[5,6]}$.

Cows have a cotyledonary placenta, the fetal cotyledons being stringently attached to and enveloping the maternal caruncles, together forming the placentome. The interconnection between the fetal and maternal tissues is further spread by cotyledonary villi and subsequently microvilli at the cotyledon-caruncle interface. The processes leading to normal separation and delivery of the placenta are multifactorial and already begin before calving ${ }^{[7]}$. Since collagen links the interface together at several sites, its breakdown is likely to be a key factor in placental separation. In addition to the drastic changes in the hormonal environment around parturition (decrease in progesterone, increase in oestrogens and prostaglandin levels), that favour enzymatic breakdown of the cotyledon caruncle linkages, activation of the maternal immune response against the foetal membranes has been attributed an important role in the final loosening process of the placenta.

Manual removal of the retained membranes is no longer recommended and is potentially harmful. Trimming of excess tissue that is objectionable to animal handlers and contributes to gross contamination of the genital tract and causes infectious endometritis. The use of oxytocin is of questionable value 24 hours after calving because by this time, the response to oxytocin becomes poor ${ }^{[8]}$. Unfortunately, in general in buffalo practice, the veterinarian is not consulted until after $24 \mathrm{~h}$ of the retention of fetal membranes because until then the farmer has hoped for a spontaneous expulsion. The layman's practice of tying a weight on the placenta should be discouraged because the weight causes the buffalo to strain and results in premature and incomplete breaking of placenta, leaving a part of it still in the uterus. This weight may also cause invagination of the uterine horn and prolapse of the uterus may occur. 
Sufficient intrauterine and parenteral antibiotics [9, 10$]$. Should be administered to promote uterine contractions and prevent uterine infection subsequent to manual removal of placenta the concentrations of prostaglandin $\mathrm{F}$ metabolites are known to be lower in buffaloes retaining their foetal membranes compared to buffaloes that had uneventful parturitions ${ }^{[11,12]}$. But the medicine is costly, calls for the help of veterinarian.

A new approach for the treatment of retained foetal membranes is the injection of collagenase into the umbilical arteries in cattle ${ }^{[8]}$ but has not yet been used in buffaloes because such an approach can be carried out in animals immediately after calving. Treatment with Allopathic drugs are costly and ineffective and requires long course so an effective and cheaper treatment with homeopathic remedy Pyrogenium were investigated.

\section{Materials and methods}

Thirty-three affected buffaloes referred to mobile clinic of procurement and milk union Tiruvendram, Kerala during 1992to 2002 and animals brought to Sreepathi veterinary services, Kadapa of Andhra Pradesh during 2010-2021, were included in the study. (Table 1) Pyrogenium 200C was purchased from local homeopathy chemist. The remedy Pyrogenium was selected basing on the close similarity of rubrics of Pyrogenium on female sex organs with the symptoms of retention of placenta.

They are Septic infection after child birth, septicaemia following a miscarriage with foetus or placenta retained and decomposed, foetid lochia, fever, menses horribly offensive carrion like. Uterine haemorrhage of bright red blood with dark clots, swollen genitalia, straining ${ }^{[13]}$. The remedy was given orally BID for 3 to 7 days till the uterine discharge was stopped. The selected remedy was given orally after carging with sugar lobules or directly given orally 5-10 drops.

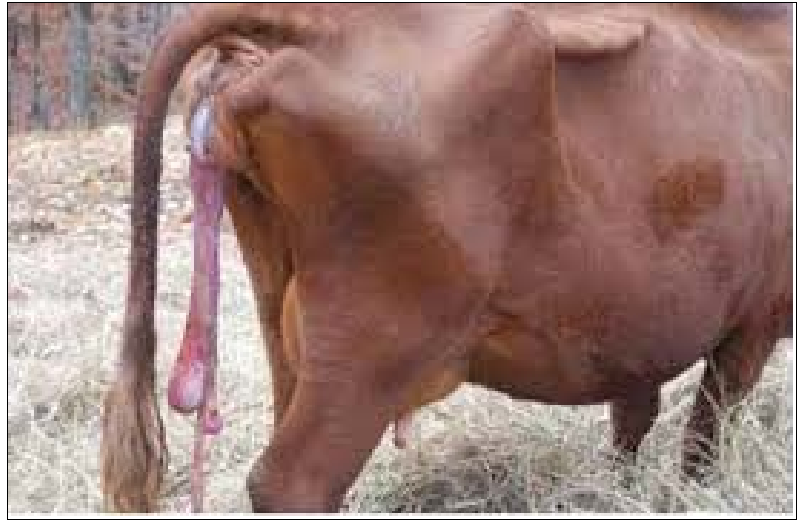

Fig 1: Retaine Place

Table 1: The table shows in number of animals, place period of study

\begin{tabular}{|c|c|c|c|c|c|c|}
\hline $\begin{array}{l}\text { S. } \\
\text { no }\end{array}$ & animals & Method & $\begin{array}{c}\text { Number of } \\
\text { animals }\end{array}$ & Place & $\begin{array}{l}\text { Period of } \\
\text { study }\end{array}$ & Results \\
\hline 1 & Cows & Removed manually & 10 & TRCMPU Ltd P\&I sub office, Kilimanoor, Kerala & $1992-2002$ & \multirow{3}{*}{$\begin{array}{l}\text { Septicaemia under control in a } \\
\text { day and uterine involution } 7 \\
\text { days, in cases of placenta } \\
\text { removed manually }\end{array}$} \\
\hline 2 & Cows & Not removed & 23 & TRCMPU Ltd P\&I sub office, Kilimanoor, Kerala & 1992-2002 & \\
\hline 3 & cows & Removed manually & 24 & Sreepathi veterinary services, Kadapa (AP) & $2010-2$ & \\
\hline 4 & cows & Not removed & 16 & Sreepathi veterinary services, Kadapa (AP) & $1992-2021$ & \multirow{6}{*}{$\begin{array}{l}\text { The placenta has in certain } \\
\text { cases fallen the next day or in } \\
\text { 3-5 days in majority of the } \\
\text { cases, in cases of placenta not } \\
\text { removed }\end{array}$} \\
\hline 5 & Buffaloes & Removed manually & 2 & TRCMPU Ltd P\&I sub office, Kilimanoor, Kerala & $1992-2021$ & \\
\hline 7 & Buffaloes & Removed manually & 3 & Sreepathi veterinary services, Kadapa (AP) & $1992-2021$ & \\
\hline 8 & Buffaloes & Not removed & 33 & Sreepathi veterinary services, Kadapa (AP) & $1992-2021$ & \\
\hline 9 & Ewes & Not removed & 28 & Sreepathi veterinary services, Kadapa (AP) & 1992-2021 & \\
\hline 10 & Does & Nor removed & 14 & Sreepathi veterinary service, Kadapa (AP) & $1992-2021$ & \\
\hline
\end{tabular}

\section{Observation and Results}

In cases of placenta not removed, it was observed that Septicaemia under control in a day and uterine involution occurred within 7 days. In case of manually attempted, there will be certain remanets, the remnants were fallen within 35 days in majority of the cases in majority of case, reproductive health was improved considerably, the discharge stopped within a week. The milk production was increased. Breeding health was improved with no repeaters. The Septicaemia under control in a day and uterine involution 7 days, in cases of placenta removed manually. The placenta has fallen the next day or in 3-5 days in majority of the cases, in cases of placenta was not removed. (Table 1).

\section{Discussion}

As there is close similarity between symptoms of Retained Placenta and rubricks of Pyrogenium, the remedy performed excellently. The medicine is cheaper. The farmer himself can administer the medicine. It can minimise the administration of antibiotics and antipyretics. It is evident form the present study that non-removal of retained placenta and use of Pyrogenium, is very good extension strategy to minimise the infection, trauma and bleeding.

\section{Conclusion}

It can be concluded that non removal of placenta and use of pyrogenium is best extension strategy and the medicine was effective, cheaper when compared allopathy, when Pyrogenum 200C was given BID for 3to 7 days until the discharge was ceased.

\section{References}

1. Wetherillt GD. Retained Placenta in the Bovine. A brief review. Can. vet. J. 1965;6(11):290-294.

2. Roberts SJ. Veterinary Obstetrics and Genital Diseases (Theriogenology). 2nd Edition. New York, USA: Literary Licencing. 1971.

3. Markusfeld O. Factors responsible for post parturient metritis in dairy cattle. Vet Rec. 1984;114:539-542.

4. Bendixen PH, Vilson B, Ekesbo I, Bendixen PH, Vilson B, Ekesbo I. Disease frequencies in dairy cows in Sweden. II. Retained placenta. Prev Vet Med. 1987;4:377-s.

5. Ahmed WM, Amal R, Abd El Hameed HH, et al. Investigations on retained placenta in Egyptian 
buffaloes. Global Vet. 2009;3:120-124.

6. Gupta D, Pandit RK, Jogi S, et al. Retention of placenta in relation to parity, season and sex of calf in Murrah buffaloes. Buffalo Bull. 1999;18:5-7.

7. Beagley J, Whitman K, Baptiste K, Scherzer J. Physiology and treatment of retained fetal membranes in cattle. J Vet Intern Med. 2010;24:261-268.

8. Eiler H. Retained placenta. In: Youngquist RS Ed. Current Therapy in Large Animal Theriogenology. WB Saunders Philadelphia. 1997.

9. Nakhashi HC, Suthar BN, Vadodaria VP, et al. Post abortion and post-partum breeding efficiency in Mehsani buffaloes retaining fetal membranes. Indian J Anim Reprod. 2006;27:96-97.

10. Kunbhar HK, Aziz-Ul lah Memon, et al. Incidence of placental retention in Kundhi buffalo around Tandojam Pakistan. Pak J Life Soc Sci. 2011;9:21-23.

11. Mishra DP, Prakash BS. Validation of a 13, 14dihydro-15-keto PGF (2alpha) enzyme immunoassay and its application fEiler or reproductive health monitoring in postpartum buffaloes. Anim Reprod Sci. 2005;90:85-94.

12. Taha MB, Azawi OI. A preliminary study of endometritis in Iraqi buffaloes. Iraqi $\mathrm{J}$ Vet Sci. 2003;56:201-208.

13. Murphy R. Pyrogen in Lotus Materia Medica, second edition, pub B Jain Publishers (P) Ltd, New Delhi. 2006, 1436-1340. 